\title{
Venus Tesserae: \\ The importance of Venus tesserae and remaining open questions
}

\author{
White Paper
}

Jennifer L. Whitten ${ }^{1}$, Martha S. Gilmore ${ }^{2}$, Jeremy Brossier ${ }^{2}$, Paul K. Byrne ${ }^{3}$, Joshua J. Knicely ${ }^{4}$, Suzanne E. Smrekar ${ }^{5}$

${ }^{1}$ Dept. of Earth and Environmental Sciences, Tulane University, New Orleans, LA 70118 jwhitten1@tulane.edu, 504-862-3257

${ }^{2}$ Dept. of Earth and Environmental Sciences, Wesleyan University, Middletown, CT 06459

${ }^{3}$ Marine, Earth, and Atmospheric Sciences Dept., North Carolina State University, Raleigh, NC 27695

${ }^{4}$ Geophysical Institute, University of Alaska Fairbanks, Fairbanks, AK 99775

${ }^{5}$ Jet Propulsion Laboratory/California Institute of Technology, Pasadena, CA 91024

All cosigners for this white paper are listed here. 
Tesserae are some of the oldest terrains on Venus and, depending on the chronology model used, correspond to an age of $420 \mathrm{Ma}$ to $1.1 \mathrm{Ga}$. This average tessera age overlaps with 3D climate simulations [Way et al., 2016] that show Venus was more habitable $\sim 1-3$ Gyr. Thus, the tesserae may have formed during a period with substantially different climactic conditions than today and may even preserve a record of this more temperate climate. Evidence indicates that during tessera formation the lithospheric thermal gradient and surface strain rates were higher than today [Brown and Grimm, 1997]. Thus, tesserae represent a record of a substantially different Venus from what is observed today. The identification of multiple tesserae morphologies [e.g., Vorder Bruegge and Head, 1989; Bindschadler and Head, 1991; Hansen and Willis, 1996] hints at several processes that formed tesserae, rather than one mechanism. Observations reveal just how complex the tesserae are and how much information is likely preserved in these materials; tesserae hold the oldest record of the climate and internal processes on Venus. Because of the potential of tesserae to preserve earlier climate conditions, it is imperative to send additional spacecraft to Venus in order to address major outstanding questions, most especially: What rock type(s) compose the tesserae? How did the tesserae materials form?

Tesserae were first identified on Venus from the Venera 15 and 16 datasets and referred to as "parquet" terrain due to their heavily deformed morphology [Barsukov et al., 1986; Basilevsky et al., 1986]. Tesserae cover 7.3\% [Ivanov and Head, 2011] of the surface of Venus and are identified by the presence of two or more sets of intersecting tectonic structures (graben, fractures, ridges). A diagnostic characteristic of tesserae is their high radar backscatter cross-section, thought to be a consequence of ubiquitous tectonic structures at the Magellan pixel resolution $(\sim 100 \mathrm{~m})$ [Bindschadler and Head, 1989]. Individual deposits of tesserae vary in size from a few tens of kilometers to a few thousand kilometers in diameter [Ivanov and Head, 1996] and are generally concentrated in the northern hemisphere in certain regions of Venus, such as Ishtar Terra, Thetis, Ovda, and Alpha tesserae, and between Beta and Phoebe regiones [Ivanov and Head, 1996, 2011]. Tesserae materials are extensive and unique among geologic units on Venus, with many of their characteristics unknown, including types/morphologies, stratigraphy, formation, and composition.

\section{Morphology}

While tesserae are generally identified by their radar brightness and the presence of multiple intersecting sets of tectonic features, these materials do have distinct differences in morphology, both within and across the various tessera deposits. Several researchers have developed different morphologic classification systems for the tesserae [Vorder Bruegge and Head, 1989; Bindschadler and Head, 1991; Hansen and Willis, 1996] which are focused on the spacing, orientation, and tectonic fabric type (i.e., ridge vs. trough vs. graben). Variations in the morphology of tesserae across Venus suggest that subsections of these materials were formed independently and then these smaller deposits accreted to form a larger highland deposit [Vorder Bruegge and Head, 1989; Ivanov and Head, 1996; Romeo et al., 2005]. The observed variations in tessera morphology suggest that they may not have all formed by the same tectonic process(es) and brings into question whether tesserae should be considered a single global unit underlying the volcanic plains [Bindschadler and Head, 1991; Hansen and Willis, 1996]. High-resolution imagery ( 6 $\mathrm{m} / \mathrm{pixel}$ ) of the surface of Venus, in particular of the tesserae, would facilitate a better understanding of their surface morphology, and provide observations that would inform formation models. 


\section{Age and Stratigraphy}

Tesserae are interpreted as the oldest materials on the surface of Venus [e.g., Sukhanov, 1992; Herrick et al., 1994; Basilevsky and Head, 1998; Ivanov and Head, 2011] based on their stratigraphic relationship with surrounding low-lying plains materials, which embay most tessera margins [e.g., Ivanov and Head, 1996]. The impact crater record preserved across the surface indicates that there is a higher spatial density of craters $>16 \mathrm{~km}$ in diameter in the tesserae, but this result is not statistically significant due to the low total number of craters on Venus [Ivanov and Basilevsky, 1993; Herrick, 1994; Strom et al., 1994]. However, the crater population superposed on the tesserae is not highly deformed [Basilevsky and Head, 1998], suggesting that the currently observed population formed after the major stage(s) of deformation [Gilmore et al., 1997]; few craters that impacted into tesserae prior to the end of the period of deformation are preserved [Ivanov and Head, 1996; Gilmore et al., 1997]. These crater spatial density values and the morphology of the impact craters suggest that deformation of tessera ended between $420 \mathrm{Ma}$ and 1.1 Ga [Ivanov and Basilevksy, 1993; Gilmore et al., 1997], depending on the assumptions for the average surface model age of Venus [e.g., Phillips et al., 1992; Strom et al., 1994].

The absolute age of tesserae, and the stratigraphic history of Venus, is still an open topic of debate. Certain researchers favor a "directional hypothesis" for the geological history of Venus, where tesserae are all formed as a basement unit of approximately the same age [Basilevsky and Head, 1998; Ivanov and Head, 2011], while others favor the hypothesis that tesserae are locally the oldest materials and tesserae vary in age across the surface of Venus [Guest and Stofan, 1999; Hansen et al., 1999]. Stratigraphy and crater statistics show that tesserae are at least slightly older than the low-lying plains and could, therefore, preserve a record of any weathering reactions or changes in climate that may have occurred due to the large-scale eruptions of the low-lying basaltic plains. Determining the age of any material would greatly increase the understanding of the timing, rate, and duration of certain geologic processes on Venus.

\section{Formation Mechanism(s)}

In addition to there being little agreement on the age or global stratigraphic position of tesserae, the mechanism(s) of their formation is also still debated. Several theories have been put forward, including mantle upwelling [Phillips et al., 1991; Phillips and Hansen, 1998] and downwelling [Bindschadler and Parmentier, 1990; Romeo and Turcotte, 2008], as well as bolide [Hansen, 2006] formation models. At the crux of this debate is the interpretation of tectonic structures and their stratigraphic sequence. In the upwelling models, melting occurs above mantle plumes and produces a volcanic rise that later collapses due to gravity. Under this scenario, extensional tectonic features are stratigraphically older than compressional features. In the downwelling models, crustal compressional features form first when the lithosphere is downwelling into the mantle, superposed by extensional features that form after compression wanes and the tessera deposit experiences gravitational relaxation. One test of these models is the identification of the style and sequence of lineaments that are at the scale of the Magellan radar data $(\sim 100 \mathrm{~m})$ and smaller and the slopes of the walls of extensional features (e.g., graben vs. tension fractures), which are essential to understand their origin and stratigraphic position. Higher-resolution imaging and topography than is currently available are required to identify these structures and determine the stratigraphy. Identifying the formation mechanism(s) for tesserae is a necessary next step in understanding the geologic record preserved on Venus. Thus, additional missions to Venus are required to account for the formation of all morphologies of tesserae. Knowledge of tessera composition would also 
greatly assist with narrowing down possible formation mechanisms. These measurements are best suited to orbital missions, with global or near-global coverage from radar instruments.

\section{Composition}

The composition of tesserae has been proposed to be either basaltic [Ivanov, 2001], or partially basaltic [Gilmore and Head, 2000], like the surrounding low-lying plains, or more silicic, perhaps even granitic [Nikolaeva et al., 1988; Hashimoto et al., 2008; Helbert et al., 2008; Mueller et al., 2008; Basilevsky et al., 2012; Gilmore et al., 2015; 2017]. Early studies of Venus proposed a feldspathic crustal composition for tesserae based on the hypsometric curve derived from the Pioneer Venus altimetry data [Nikolaeva et al., 1988] and by inference from the Venera 8 chemical data [Nikolaeva et al., 1990]. Romeo and Turcotte [2008] argued that tesserae topography is consistent with their being buoyant survivors of global resurfacing events and thus comprise lowdensity crust. Modeling the surface composition of Venus using Magellan SAR data produced a range of dielectric constant values between 2 and 8, where the tesserae are not obviously distinct from the plains [Campbell, 1994]. Kreslavsky et al. [2000], however, attributed differences in radar brightness in tessera compared with low-lying plains to lower dielectric permittivity and density of tesserae due to felsic compositions or enhanced weathering.

More recent analyses from the European Space Agency's Venus Express (VEx) mission used near infrared emissivity data from the Visible and Infrared Thermal Imaging Spectrometer (VIRTIS) instrument. VIRTIS emissivity is interpreted as the ratio of locally observed to modeled radiance at $1.02 \mu \mathrm{m}$ and is also referred to as the flux anomaly or radiance anomaly) as well as the $1.01 \mu \mathrm{m}$ Venus Monitoring Camera (VMC) data to more directly probe the composition of tesserae. Low VIRTIS brightness values, i.e. flux anomaly, have been interpreted to indicate the presence of more felsic materials [Helbert et al., 2008; Gilmore et al., 2015]. These and other recent studies [e.g. Hashimoto et al., 2008] have suggested that the tesserae are different in composition from the low-lying plans and that because emissivity at $\sim 1 \mu \mathrm{m}$ is relative to $\mathrm{Fe}^{2+}$ content in minerals, the tesserae are composed of more silicic materials than the low-lying plains.

The instruments on the VEx mission were designed to measure the atmosphere, meaning that measurements of flux anomaly, or emissivity, are dependent on reliable atmospheric scattering models, measurements of atmospheric parameters, and topography, which is used as a proxy for surface temperature. Interpretations of the VIRTIS flux anomaly are complicated because elevation values cannot be disentangled from surface temperature effects and having only one wavelength makes it difficult to unambiguously identify geologic materials [Mueller et al., 2008]. That said, models are reliable enough to determine that there are substantial differences between the low-lying plains and many tesserae. Low flux anomaly values are associated with some tesserae and certain areas of low-lying plains; these variations in flux anomaly could mean that felsic compositions are not just confined to tessera [Mueller et al., 2008]. To complicate matters further, rather than compositional differences, variations in flux anomaly could also represent variations in weathering [Helbert et al., 2008] or variations in grain size. Direct measurements of the tesserae surface chemical composition and mineralogy at multiple wavelengths are needed to reliably determine the composition of tesserae and how that composition varies across Venus. 


\section{Emissivity and Backscatter Coefficient}

Spatial trends observed in Magellan data hint that there are either differences in the composition of tessera or differences in the weathering rates or processes across tesserae. Magellan emissivity data has revelated four distinct patterns in tesserae radiophysical properties: (1) decreasing emissivity with elevation at $>6053 \mathrm{~km}$ followed by a sharp increase at the highest elevations (above $\sim 6056 \mathrm{~km}$ ), (2) a lower elevation trend where this turnover happens at $\sim 6053 \mathrm{~km}$, (3) relatively consistent emissivity values across all elevations, and (4) no observed trend [Gilmore et al., 2019]. These variations in radar emissivity across tesserae could indicate differences in rock type, atmospheric composition, and/or age, or a combination of all these variables.

Recent work focused on characterizing the radiophysical properties of tesserae surfaces via calculations of backscatter coefficient, using Magellan and Earth-based telescopic datasets [Campbell et al., 2015; Whitten and Campbell, 2016], has also identified differences across tesserae. Backscatter coefficient is the radar scattering cross section per unit area and quantifies how efficiently a surface scatters energy. Backscatter variations, both radar-bright and radar-dark, exist that are not correlated with impact crater ejecta or other geologic processes are observed in tesserae across Venus [Whitten and Campbell, 2016; Whitten and Campbell, 2019]. Thus, the Magellan SAR data are showing inherent differences in the tesserae materials, an observation that is supported by emissivity results. Spatial patterns observed in Magellan emissivity data are $\sim 2$ orders of magnitude lower resolution than the SAR image data, making their comparison difficult.

Whether tesserae are basaltic or more silicic has important implications for the geologic history of Venus, specifically the role of water in the planet's interior. The exact type of felsic rock, whether a granite or an anorthosite, will also affect predictions of the geologic history of Venus. Typically, granite and other highly silicic rock types (e.g., syenite) are formed in the presence of water [Campbell and Taylor, 1983]. While water does reduce the solidus temperature, production of granitic liquids will still occur without liquid water [Bonin, 2012; Shellnutt, 2013]. Water can promote the formation of silica-rich liquids, thus controlling the quantity or volume of granitic liquid produced [Bonin, 2012]. Venus does not currently have water on its surface, but the possibility of an ocean early in its history [Donahue et al., 1982] could have facilitated the production of large enough quantities of granite to correspond to the tesserae observed today.

Anorthosite is another plausible tessera rock type based on the results of the VEx flux anomaly measurements [Mueller et al., 2008; Gilmore et al., 2015]. However, the production of anorthosite on Venus faces several challenges that indicate it is not a probable composition for tesserae. Plagioclase floatation is not expected on a Venus-sized planet with a magma ocean and, if a plagioclase-rich crust did somehow form, it would founder before it could be preserved as crustal material [Elkins-Tanton, 2008]. Regardless of the exact silicic composition, all the proposed compositions are intrusive igneous rocks that require erosion to expose the parent materials to tessera deposits; large-scale eruption of rhyolite for tessera formation would avoid this added erosional component.

\section{Recommended Measurements}

High-resolution radar and topography measurements of Venus are equivalent to the CTX camera ( $\sim 6 \mathrm{~m} / \mathrm{pixel})$ and MOLA ( $\sim 500 \mathrm{~m} / \mathrm{pixel})$ topography at Mars and would be just as groundbreaking in our understanding of the geologic evolution of Venus. Magellan SAR $(\sim 100 \mathrm{~m})$ and topography 
( $\sim 10 \mathrm{~km})$ resolutions, are simply not good enough to distinguish the type, form, and attitude of tectonic structures superposing tesserae and volcanic deposits, and establish stratigraphic position, all of which must be determined to test models of tessera formation. Tesserae also contain sediment whose origin, depth, movement and particle size require meter-scale multi-polarimetric imaging and elevation data to interpret. Additionally, higher-resolution topography will provide constraints for surface temperature that will be critical for calculating emissivity values.

The open question of tessera composition is critical to our understanding of the crustal and climatic evolution of Venus. Tesserae are the oldest preserved rocks on Venus, and our only access to materials that may have formed while Venus was habitable. One key dataset required to constrain tesserae composition and determine whether silicic rocks that require abundant water and crustal recycling for their formation are present is multispectral measurements of mineralogy. Orbital 1 $\mu \mathrm{m}$ emissivity measurements, which are related to iron content, can yield a global map that serves as a proxy for mineralogy. VEx results already show the utility of spectral measurements at a single wavelength [e.g., Helbert et al., 2008; Gilmore et al., 2015]. Multispectral measurements would provide enough information to more accurately characterize the specific mineralogy of geologic units on Venus. Maps of spectral variability (at one or more wavelengths) can provide insight into the compositional variability of tesserae and plains, which informs our understanding of the tessera formation processes (e.g., aggregation, global basement) and helps select targets for landed assets.

Confirmation of chemical composition and mineralogy can only be accomplished via in situ measurement from a lander. For example, the Venus Intrepid Tessera Lander (VITaL) study was performed as part of the last Decadal survey in response to the Inner Planets Panel's recognition of the importance of tessera composition [Gilmore et al., 2010]. This mission design included a short-lived lander equipped with a Raman/LIBS system to measure the chemistry and mineralogy of multiple surface targets. Raman/LIBS has been recognized by the Venus community and NASA as critically enabling for Venus as it allows rapid measurement of multiple targets without the need to ingest materials into the lander. This technology has been funded by the New Frontiers office for development for Venus by LANL. A key insight of VITaL is that a lander can be designed to safely accommodate the rough terrain expected on the tesserae. In addition, in situ compositional measurements can be used to calibrate orbital near-infrared mineralogic measurements and reduce uncertainties in the orbital measurements. Improved imaging and topography of the surface (e.g., that proposed by VERITAS [Smrekar et al., 2019]) would better ensure mission safety.

To facilitate these proposed measurements of surface composition from orbital and ground-based systems several different technologies need to be developed. Specifically for a landed mission, high-temperature electronics, advanced power and cooling technologies need to be developed to order to sustain a surface presence on the order of a couple of months rather than a couple of hours [Hunter et al., 2019]. Not only will technologies that prolong the lifetime of a lander be required, but so will technologies that facilitate a pinpoint landing and hazard avoidance [Hunter et al., 2019], especially for a tessera lander where the terrain is particularly rough, down to the resolution of available data. A landed mission to a tessera deposit on Venus would address several major science questions identified by the Venus community, including the abundance of internal water earlier in its geologic history, crustal origin and recycling, weathering processes, and the surface evolution [O'Rourke et al., 2019]. 
Barsukov, V.L. et al. (1986) The geology and geomorphology of the Venus surface as revealed by the radar images obtained by Veneras 15 and 16, Proc. LPSC 16, JGR 91, D378-D398.

Basilevsky, A.T., Head, J.W. (1998) The geologic history of Venus: A stratigraphic view, JGR $103,8531-8544$.

Basilevsky, A.T., et al. (1986) Styles of tectonic deformation on Venus: Analysis of Venera 15 and 16 data, Proc. LPSC 16, JGR 91, D399-D411.

Basilevsky, A.T., et al. (2012) Geologic interpretation of the near-infrared images of the surface taken by the Venus Monitoring Camera, Venus Express, Icarus 217, 434-450.

Bindschadler, D.L., Parmentier, E.M. (1990) Mantle flow tectonics: The influence of a ductile lower crust and implications for the formation of topographic uplands on Venus, JGR 95, 21329-21344.

Bindschadler, D.L., et al. (1989) Characterization of Venera 15/16 geologic units from Pioneer Venus reflectivity and roughness data, Icarus 77, 3-20.

Bonin, B. (2012) Extra-terrestrial igneous granites and related rocks: A review of their occurrence and petrogenesis, Lithos 153, 3-24.

Brown, C.D., Grimm, R.E. (1997) Tessera deformation and the contemporaneous thermal state of the plateau highlands, Venus, EPSL 147, 1-10.

Campbell, B.A. (1994) Merging Magellan emissivity and SAR data for analysis of Venus surface dielectric properties, Icarus 112, 187-203.

Campbell, B.A., et al. (2015) Evidence for crater ejecta on Venus tessera terrain from Earth-based radar images, Icarus 250, 123-130.

Campbell, I.H., Taylor, S.R. (1983) No water, no granites - no oceans, no continents, GRL 10, 1061-1064.

Cutts, J.A., et al. (2019) Roadmap for Venus Exploration, VEXAG.

Donahue, T.M., et al. (1982) Venus was wet: A measurement of the ratio of deuterium to hydrogen, Science 216, 630-633.

Elkins-Tanton, L.T. (2008) Linked magma ocean solidification and atmospheric growth for Earth and Mars, EPSL 271, 181-191.

Gilmore, M.S., Head, J.W. (2000) Sequential deformation of plains at the margins of Alpha Regio, Venus: Implications for tessera formation, Meteor. Planet. Sci. 35, 667-20, 687.

Gilmore, M.S., et al. (2015) VIRTIS emissivity of Alpha Regio, Venus, with implications for tessera composition, Icarus 254, 350-361.

Gilmore, M.S., et al. (1997) Duration of tessera deformation on Venus, JGR 102, 13,357-13,368.

Gilmore M. S., et al. (2010) Venus Intrepid Tessera Lander (VITaL), Mission Concept Study Report to the NRC Decadal Survey Inner Planets Panel, 49 pp.

Gilmore, M.S., et al. (2019) Variations in the radiophysical properties of Venus tesserae: Could be the rocks? Could be the climate? LPSC 50, \#2632.

Guest, J.E., Stofan, E.R. (1999) A new view of the stratigraphic history of Venus, Icarus 139, 5566.

Hansen, V.L. (2006) Geologic constraints on crustal plateau surface histories, Venus: The lava pond and bolide impact hypotheses, JGR 111, E11010.

Hansen, V.L., Willis, J.J. (1996) Structural analysis of a sampling of tesserae: Implications for Venus geodynamics, Icarus 123, 296-312.

Hansen, V.L., et al. (1999) Tessera terrain and crustal plateaus, Venus, Geology 27, 1071-1074.

Hashimoto, G.L., et al. (2008) Felsic highland crust on Venus suggested by Galileo Near-Infrared Mapping Spectrometer data, JGR 113, E00B24. 
Helbert, J., et al. (2008) Surface brightness variations seen by VIRTIS on Venus Express and implications for the evolution of the Lada Terra region, Venus, GRL 35, L11201.

Herrick, R.R. (1994) Resurfacing history of Venus, Geology 22, 703-706.

Hunter, G. et al. (2019) Venus Technology Plan, VEXAG.

Ivanov, M.A. (2001) Morphology of the tessera terrain on Venus: Implications for the composition of tessera material, Solar Sys. Res. 35, 1-17.

Ivanov, M.A., Basilevsky, A.T. (1993) Density and morphology of impact craters on tessera terrain, Venus, GRL 20, 2579-2582.

Ivanov, M.A., Head, J.W. (1996) Tessera terrain on Venus: A survey of the global distribution, characteristics, and relation to surrounding units from Magellan data, JGR 101, 14861-14908.

Ivanov, M.A., Head, J.W. (2011) Global geologic map of Venus, PSS 59, 1559-1600.

Kreslavsky, M.A., et al. (2000) Dielectric permittivity of the tessera surface material on Venus inferred from Magellan radar data, Solar Sys. Res. 34, p. 379.

Mueller, N., et al. (2008) Venus surface thermal emission at $1 \mu \mathrm{m}$ in VIRTIS imaging observations: Evidence for variation of crust and mantle differentiation conditions, JGR 113, E00B17.

Nikolaeva, O.V., et al. (1988) Are tesserae the outcrops of feldspathic crust of Venus? LPSC $19^{\text {th }}$, abstract 1437.

Nikolaeva, O.V. (1990) Geochemistry of the Venera 8 material demonstrates the presence of continental crust on Venus, Earth, Moon, Planets 50, 329-341.

O'Rourke, J., et al. (2019) Venus goals, objectives, and investigations, VEXAG.

Phillips, R.J., Hansen, V.L. (1998) Tectonic and magmatic evolution of Venus, Ann. Rev. Earth Planet. Sci. 22, 597-654.

Phillips, R.J., et al. (1991) Hot-spot evolution and the global tectonics of Venus, Science 252, 651658.

Phillips, R.J., et al. (1992) Impact craters and Venus resurfacing history, JGR 97, 15,923-15,948.

Romeo, I., Turcotte, D.L. (2008) Pulsating continents on Venus: An explanation for crustal plateaus and tessera terrains, EPSL 276, 85-97.

Romeo, I., et al. (2005) Tectonic and kinematic study of a strike-slip zone along the southern margin of Central Ovda Regio, Venus: Geodynamical implications for crustal plateau formation and evolution, Icarus 175, 320-334.

Shellnut, J.G. (2013) Petrological modeling of basaltic rocks from Venus: A case for the presence of silicic rocks, JGR Planets 118, 1350-1364.

Smrekar et al. (2019) VERITAS: A proposed Discovery Mission, EPSC-DPS, abstract 1124.

Strom, R.G., et al. (1994) The global resurfacing of Venus, JGR 99, 10,899-10,926.

Sukhanov, A.L. (1992) Tesserae, in: Venus Geology, Geochemistry, and Geophysics, Research Results from the USSR, V.L. Barsukov, A.T. Basilevsky, V.P. Volkov, V.N. Zharkov eds., pp. 82-95, Univ. Arizona Press, Tucson, AZ.

Vorder Bruegge, R.W., Head, J.W. (1989) Fortuna Tessera, Venus: Evidence of horizontal convergence and crustal thickening, GRL 16, 699-702.

Way, M.J., et al. (2016) Was Venus the first habitable world of our solar system? GRL 43, 83768383.

Whitten, J.L., Campbell, B.A. (2016) Recent volcanic resurfacing of Venusian craters, Geology 44, 519-522.

Whitten, J.L., Campbell, B.A. (2019) Variations in the radar properties of tesserae across Venus as observed with Magellan data, LPSC 50, \#2558. 